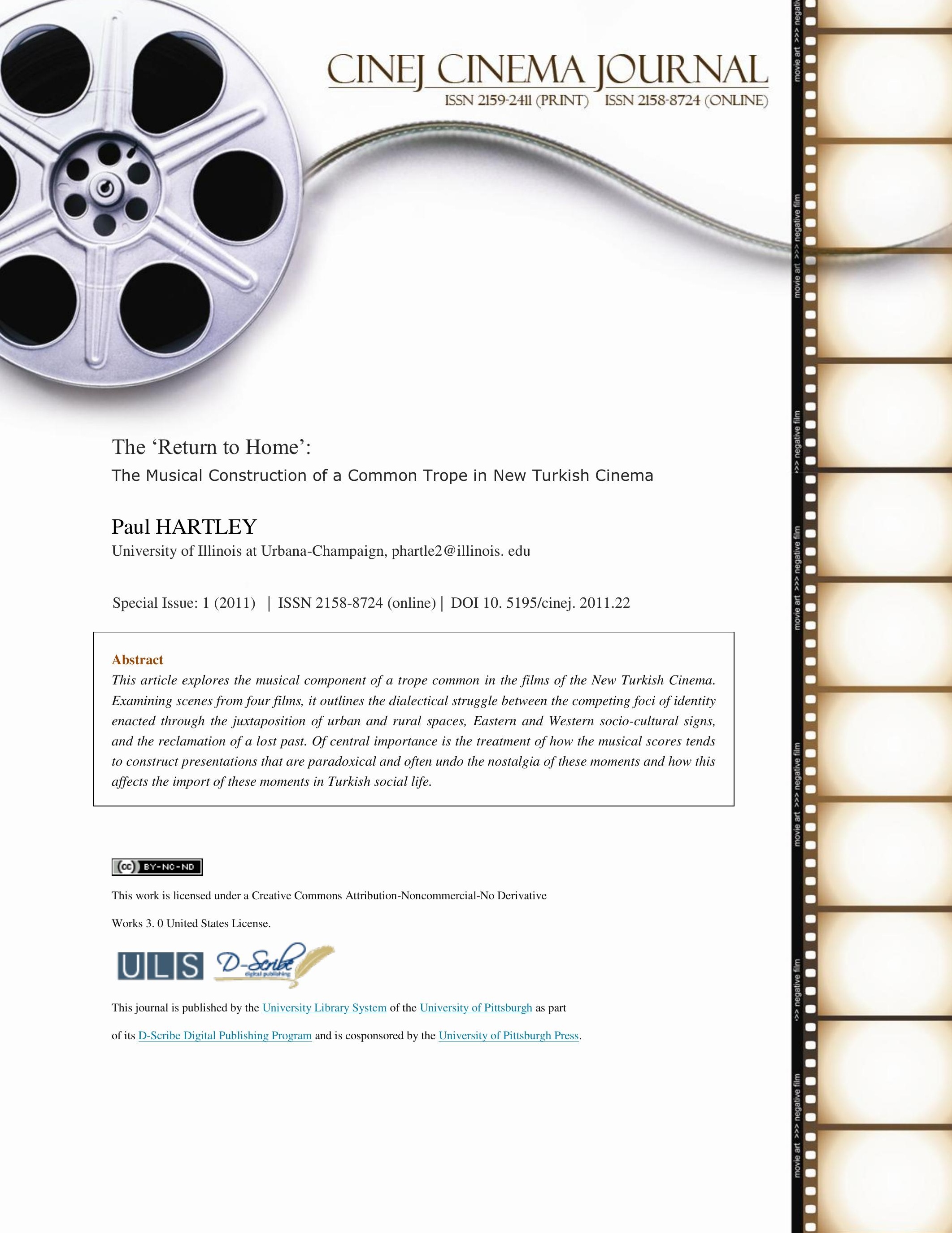




\section{The 'Return to Home': The Musical Construction of a Common Trope in New Turkish Cinema}

Dervis Zaim's 2006 film Cenneti Beklerken (Waiting for Heaven) ends with these words:

Eflatun (Grasping the shoulders of his assistant)

To return to the past means embarking on a new journey. We'll paint new European pictures. Sometimes we will use the style of miniatures. And sometimes we'll merge the two styles. Then perhaps I can start drawing miniatures again. We'll make mistakes. Like you, I hope to return to the very beginning. We'll look forward to recovering.

Here Eflatunis assuring his assistant that they will return to their work as miniature artists and painters, but he is also using the metaphor of synthesis to describe how the two will be able to continue their lives after the experiences and losses they suffered throughout the course of the film. In doing so, Eflatun, and through him Zaim, is making a connection between adesire to remain connected to the past, or even return to a time before trauma, and the need to push into a new future built by combining the past with the Western influences. While the Ottoman past and Western culture may seem to be unconnected, they are two elements within an important contemporary debate about what it is to be Turkish, and what Turkey's place is within the current socio-cultural and political landscape. Directly (and anachronistically) referencing Turkey's recent political, social, and cultural traumas and struggles, Eftalun's comments are the final statement of a film deliberately constructed by Zaim to stand as a statement regarding the Turkish peoples' difficulty with national and personal identity. ${ }^{1}$ In an interview with Gönül Dönmez-Colin, Zaim says he is concerned about Turks' inability to openly discussthe implications of identity politics and the hardening of the distinction between 'us' and 'them' in the Turkish public sphere. We see this fear expressed in Eflatun's words and throughout the film. We are to understand this sentiment asZaim's solution to transcend this difficult issue and avoid the necessary divisions that accompany the antagonism between 'us,' and 'them. ' He clearly sees the synthesis of the two through a non-judgmental process to be the best solution for Turkey's future. Dönmez-Colin notes Zaim "stresses that the film does not oppose different cultures to show them as the 'other,' but instead tries to show how different cultures mutually enrich each other." ${ }^{2}$ The combination proposed by Eflatun is clearly the expression of that ideal. But this sentiment is not entirely new. It can be interpreted as an articulation of the ideals of the very process of social and cultural engineering in Turkey that created many of the problems Zaim is trying to address. In fact, the desire to incorporate Western practices into Turkish culture has been the expressed wish of reform minded intellectuals and politicians since the $19^{\text {th }}$ century. ${ }^{3}$ Zaim's vision shares this goal, but offers a different method and purpose.

Zaim's comments demonstrate he sees his film as a space in which this critical commentary can take place. And yet, much of what Zaim set out to do within this film, as a deliberate action, is already ongoing within the larger body of works that are loosely identified as the new Turkish cinema. Many Turkish films over the last fifteen years, including others by Zaim have dealt with the tensions inherent in Turkey's discourse over identity and Turkey's place in the world. Indeed, it could be argued most films from this period deal with this issue directly or obliquely. A broad analysis of films of all genres shows the interaction between East and West, and the mechanisms of socio-cultural synthesis are routinely discussed, critiqued, and reformulated by filmmakers of all kinds. What separates these treatments from Zaim's Cenneti Beklerkenis the degree of emphasis. More often, the 
presentation of this discourse regarding identity is tangential, subtly hidden, or even perhaps accidental — the result of a nearly unconscious desire to work through these problems. Nevertheless, these issues are pervasive, and the methods of dealing with them are common enough that they appear as banal cinematic tropes which are repeated in a large number of films spread across generic boundaries.

My larger purpose here is to highlight a common the cinematic treatment of Turkey's debate regarding cultural hybridity as a ground or fixed point upon which to begin process of identification. ${ }^{4}$ Of particular importance is how these moments speak to the ideals of cultural hybridity and evoke a sometimes paradoxical nostalgia where they generate a need to return to a past that never existed or a space that has no real connection to the past. Most of all, I will show how the formal construction of these moments, with an emphasis placed on the musical cues, shows how the score for this common trope is an important locus for the discussion about 'Turkishness.' The reason for this special attention on the music is a simple one: the musical scores are the most overlooked and can bring a host of unproblematizedassociations to the audience. Often this music is more meaningful outside the reach of the narrative than the visual or narrative features of these moments. Sometimes the music destroys the meaning of the moment by creating a paradox that cannot be reconciled. What is certain is that the score itself is an important voice in how these moments are interpreted, and an analysis will identify how these moments speak to audiences.

The cinematic trope I am calling the 'return to home' is perhaps the most obvious and most common treatment of the identity politics and mechanisms of personal identification. It involves a combination of narrative, visual, and musical constructions that set the contemporary, urban, cosmopolitan Turkey against a nostalgic, romanticized presentation of rural Anatolia. In its typical form it begins by locating a character in his or her home in a city where they are put in a position where they must leave. Usually this involves placing them in some sort of conflict or danger. In order to alleviate the immediate difficulties of their circumstance, they escape to the countryside. The city, then, gives way to the interstitial space of the road, and we see them travel from the city into the interior or to the coastal villages. Most typically, they return to their parent's home, or to the village they left behind. This 'return to home' is always an emotional moment and created to be a passage from danger into safety.

The basic construction of this trope involves making a set of important distinctions between the urban and the rural space, with the distinction standing as the framework around which the other oppositions are organized. The emphasis is on making the most of relationships existing between them - although most often this means how they differ and what the disjuncture implies. First of all, the urban space (usually Istanbul) is always marked by the signs of modernity, cosmopolitanism, and Western influences. It is these very markers that are often enlisted to explain the trouble or the alienation that forces the characters to leave. The passage from the city to the rural space is always some sequence showing travel. In most films, the camera focuses on the road and the movement of a lone car moving from the urban spaces to the open landscape of Anatolia. The colours begin to change - usually from the greys and blacks of the city to the browns and greens of the village - and the intrusion of yellow- or orange-hued natural light accompanies a change in cinematographic approach, i. e. longer shots, lingering establishing shots, crane/helicopter shots etc. Finally, the character's family home becomes the center of the action. In this way, the 'return to home'is usually a literal return to home, and the troubles of the city are replaced by the relative safety of the family. Thus, the return to home is a restorative act, where the characters can reclaim something they have lost in the city and the chaos of the modern world.

While this trope appears mostclearly in plot devices and visual presentations, it is with the addition of the musical score, or rather the accompanying cues, that these moments reach their most affective and persuasive potential. This is in part because contemporary Turkish musical practice is itself the product of a long, and often 
divisive, process of "modernization" - which in this case means Westernization. ${ }^{5}$ Interestinglythe combinatorial or dialectical nature of the musicin the scores is ignored or overlooked. There are several possible reasons for this. The first is that audiences simply are no longer actively aware or interested in the history of the Westernization of Turkish music. ${ }^{6}$ This means Turkish scores display some interpretation of Eflatun's synthetic process in each film. That the scores often reinterpret, undercut, or underscore the narrative or visual presentations of the discourse surrounding the East/West dichotomy then also passes unnoticed.

In her book The Future of Nostalgia Svetlana Boymsets nostalgia within a framework of loss and impossibility when she says "nostalgia is a sentiment of loss and displacement, but it is also a romance with one's own fantasy." It is therefore a consequence of the absence of something tangible or fictional. Later, she changes her tack and demonstrates it is not simply a symptom of loss but of an act of destruction, "the nostalgic desires to obliterate history and turn it into private or collective mythology, to revisit time like space. .." This last comment holds much wisdom because it captures not only the desire to defy the passage of time by turning what once was into what will always be, but also the tendency to conflate time and space while building this mythos. Thus, the past and the 'original' home are always one and the same - often one can stand for both. We see this when past and present, or past and future (and all of the various permutations, e. g. modern/ traditional), become interchangeable with urban and rural or home and not-home. Our tendency to commit this sleight of hand loads these binaries with a great deal of import beyond their immediate boundaries. If past, present, and future can be recast as landscapes to be inhabited, then actual landscapes can capture and hold the past. The 'return to home' trope depends on the validity of this conflation. It produces a binary which sets the modern against the pastoral.

Boym, amongst others, sees the pain of nostalgia caused by the loss of home as a ground for common bonds, but the return to home as the basis for division. ${ }^{9}$ The loss brings people together, but by affecting a return to what was lost establishes the old divisions of 'us' and 'them'. It seems, however, this effect is only true for actual returns. A cinematic presentation of nostalgia fosters only the unifying power of this sentiment. The divisive effects of the reclamation of what was lost are lost in the cinematic presentation of a common myth. Because nothing was actually regained, the presentation evokes the nostalgia without its aftereffects. This has many implications when considering what the ubiquity of the 'return to home' trope in Turkish cinema means. First of all, it implies a mythos of migrancy and loss broad enough to apply to all Turks. It holds contemporary Turks are separated from their 'origins,' whether they be imagined or literal. They are joined by a common memory which began with movement from the interior, where the 'origins' lie, to the cosmopolitan, urban periphery (despite the fact this orientation is back to front for many Turks). It forces acknowledgement of a Turkish 'origin,' like the one described by the nineteenth-century intelligentsia and Kemalist reformers, notably Ziya Gökalp, where 'Turkishness' is rooted in Folk culture. ${ }^{10}$ In short, Turkish cinema presents audiences with a form of quiet, soft-nationalism like that described by Michael Billig. ${ }^{11}$ Unlike the statist nostalgia described by Esra Özyürek, the 'return to home' is a unifying sign speaking of the truth of Turkish unity without commenting on the validity of the state's assertion of socio-cultural unity being a ground for sovereignty and governance. ${ }^{12}$ That it is largely unquestioned demonstrates how this nationalist myth has become a banal sign of socio-cultural unity. It speaks of a lost innocence or childhood which stands as a universalization of the experience of separation and loss. AsumanSuneridentifies the parent-child component as being extremely important in the genre she calls nostalgia film. ${ }^{13}$ But this trope is not limited to nostalgic melodramas. Rather is a common strategy for most filmmakers to speak quietly of a Turkish 'heim,' closely connected to family, which offers safe haven and brings individuals back to the beginning to allow them to recover, as Eflatun suggests it will. The combinatorial and often idiosyncratic nature of the trope demonstrates that while the details may change, the banality of this truth endures and allows this message to pass unquestioned. 
Çagan Irmak’s 2005 film Babam ve Oğlum (My Father, My Son) provides a perfect point to begin a closer examination of the 'return to home' trope because itmakes heavy use of dichotomies asserting the inherent differences between rural/urban, traditional/modern, and origins/contemporary Turkey pairings in its relatively orthodox presentation of this trope. Although this film was an emotional melodrama - an entertainment genre not known for its treatment of controversy - it was set within the context of social and political upheaval arising in the aftermath of the 1980 military coup. The film's opening sequence shows the leftist journalist Sadik's (Fikret Kuskan) and his pregnant wife desperately looking for medical assistance as the military occupies the city. She dies giving birth to their son. Sadik is arrested and suffers tortureat the hands of the new government during the titles sequence. Following this opening, the film focuses on Sadik's return to his family home after years of working in Istanbul. He is dying from the health problems caused by the torture and is returning home to bring his son Deniz (Ege Tanman), now seven years old, to meet his estranged family. As we learn later, Sadik defied his father's wishes to pursue his career in the city. He chose to leave the rural, traditional life of his parents behind. His return is therefore not a happy one. This aside, the sequence depicting his return to the family's rural home can serve as an archtype for the trope, particularly in the complicated way it connects the urban/ rural and modern/ traditional dichotomies to the individual/ family pairing.

The 'return to home' sequence begins with Sadik and Deniz (father and son) in their small apartment in the city. Their life appears happy enough, but clearly something is wrong. Sadik is brooding and preoccupied. Eventually he tells Deniz they are going to meet his grandfather over a particularly grim breakfast. The moment is made all the more unfortunate because of the washed out blue-grey and white tones of the apartment. Following a jump cut, we follow them onto a train where they begin the move from the city to the countryside. They spend some pleasant time together on the train before finally arriving in the unnamed Aegean village where Sadik grew up. The interstitial space provided by the train compartment serves as a separator between the urban and rural spaces. Then, a jump cut replaces the train's interior with a wide establishing shot of fields, groves of trees, and a house in the distance. The colours are immediately brighter and the green crops in the fields make a stark contrast with the mise-en-scene of the city. With the cut from train to the rural landscape surrounding the family home, a cue of melodic music, unmistakably "Turkish," because of its instrumentation, surface stylistic features, and monophonic construction, breaks the silence and deepens the visual richness of the moment.

Before this point in the film, the music has had an orchestral setting consisting of short cueswhich would not be out of place in any 'Western' film following a Hollywood or European model. This polyphonic, orchestral score has set the tone of the film until this point. Against this sonic background, this new cue is the first one with an unmistakable 'Turkish' sound, and its introduction marks a change in the sonic realm of the film. The music is called "Trip Around the Aegean" and written by Evanthia Reboutsika, a Greek musician and composer who won a 'World Soundtrack Award' for the score in $2006 .{ }^{14}$ Newly composed for the film, the cue is performed by a typical variant of a nightclub ensemble, or an urban Roma fasl, an urban genre of music closely related to the more patrician light classical Ottoman musical practice but with a slightly different repertoire and socio-cultural connotations. Today this ensemble is typical for anything from historical performances to the light-pop music that more closely adheres to the Turkish musical traditions. The cue features a typical ensemble of violins, ud, kanun (a plucked trapezoidal harp played flat on the lap) a goblet-shaped drum called the darabuka, a large frame drum called a def. The sound of this ensemble is unmistakable and easily understood by a Turkish audience, and the change in instrumentation alone is a sufficient reason to examine the cue at this point. The melody is in buselikmakamı a mode which has a pitch content functionally identical to a natural minor scale. Consequently the melody can convincingly be set in a stylistically 'Turkish' idiom and also be malleable enough that it can be reset in a western idiom - which it is later on in the film. It is a significant moment, both in terms of the narrative and 
because the cue is the first to be coded 'Turkish,' through its stylistic components: i. e. melodic content, instrumentation, performance practice. The placement of the cue immediately makes a connection to the rural space. The simultaneous disjuncture in the score and in the visual presentation cements the relationship. Musically, the moment is made all the more significant because it is the first statement of a theme which becomes a leitmotif that permeates the rest of the film.

This music continues to play as Sadik and Deniz walk down the dirt, tree-lined road leading to Sadik's family home. Sadik is clearly apprehensive about returning home and he walks down the path with fear clearly marking his face. The music is the only sound we hear until Deniz complains his father is squeezing his hand too hard. Close-up shots show the trepidation on Sadik's face as the theme repeats with a thicker setting intensified by increasing the instrumental forces. Sadik himself now embodies the move from the rural interior to the cities. Thus, the disjuncture between the urban and rural spaces introduced in the musical and visual construction is mirrored in Sadik's obvious alienation from his rural origins. The pathos of the music is clearly designed to emphasize the heavy emotion of the moment, and the score tells the audience more about the moment than any other field of the film.

The narrative thrust of this moment plays out the trope where characters return to their home or their origins. All fields of the film, narrative, visual, and musical work together to establish the validity of the connection and the impact of this return. However, they also speak outside the diagetic world of the film in that these cinematic truths impact how viewers consider the actual distinction between the urban and rural spaces. Outside the film, audiences already associate urban spaces and rural spaces with similar musical signs. The 'normality' of this cinematic moment is possible exactly because it is also true in daily life. What is vital here is the use of a cue which has an internal paradox which damages the authenticity of the past. It is an, perhaps accidental, expression of the carefully created musical history envisioned by nationalist thinkers, in that it establishes an "origin" that urbanized Turks can rely on, and even literally return to.

Here, Irmak and Reboutsika construct the most typical version of the 'return home,' and I can therefore outline the musical features of the trope. The cue is set apart in the score as it is the first music not set in a Western symphonic arrangement, and this return is, thus, cast sonically as a move from the modernized and Westernized conventions of the urban space to the traditional Turkish roots of Anatolia. This connection allows for a nostalgic conflation of the notion of one's origins, or past and the family within the rural space. The music that scores these scenes must bear easily identifiable sonic signs of either a real or an artificial folk culture. The artificial folk culture can be the product of governmental reforms or cinematic constructions. In either case, the musical content relies on understandable sonic signs that evoke unreconstructed Turkish life in rural Anatolia. Because these signs are most often not more deeply-rooted musical features, such as pitch content, rhythmic structure, or large-scale song forms, this music usually involves more superficial signals. Specific instruments, such as the zurna, davul, and the sazare already established signs of this rural cultural sphere and are consequently most commonly enlisted to evoke the correct interpretation. Because the conflation of the past and rural sphere has now very deep penetration, even instruments like the ney, an instrument once associated with the urbane and cosmopolitan Mevlevi dervishes, can serve to score homecomings to a rural home. That this is now true suggests the repetition of this trope is actually a site where the validity of these connections is created and cemented.

Remboustika's music does not itself participate in the larger dialogue about Turkish identity identified by Zaim above. While her cue bares stylistic markers clearly identifying it as 'Turkish music' it does not engage in this debate directly or try to synthesize the Western and Turkish idioms along the lines articulated by Eflatun. However, other musical cues used in different variants of the 'return to home' trope attempt to forge a synthetic music from formal elements signifying each side of the modern/traditional, rural/urban dichotomies. They are 
themselves strategies to realize Eflatun's ideal. One such example can be found in Ulaş Ak's film Dün Gece Bir Rüya Gördüm, or "Last Night I Saw an Angel" (2006). It is a romantic-drama about the upstanding and somewhat naïve Deniz (Emre Kinay) and the troubles that beset him when he falls hopelessly in love with Lale (Pelin Batu), a troubled woman involved in a world of gangsters and drugs. The film follows the two through the beginnings of their troubled love affair, and focuses on his attempts to redeem her. There are two homecomings in the film. The first comes when Deniz takes Lale to his family home in rural Anatolia to try to get her away from the danger of the city. The second happens when Lale seeks refuge by returning to her father's apartment in the city. Each of these moments is scored with music distinct from the rest of the score that evokes a nostalgia for the past and the myth of 'origin'. The two homecomings are set apart musically because one makes use of a contemporary setting of a simple melody evoking Turkish musical practice (but not entirely), whereas the other sets an American song.

The first statement of this trope follows the same format of the earlier example in Babam ve Oglum. Feeling the need to take Lale to a safe place after she has been threatened by some gangsters, Deniz takes her to his family home in the village where he grew up. Like the other example, this return to home begins in the city, follows the two as they travel between the city and the rural space, and ends as they arrive in a clearly rural landscape.

They leave the city at night. This trip is shot with a static camera looking out over their shoulders from the backseat of his carinto the darkness ahead of them. We see the road and the street signs as Deniz drives along the highways and out of the light cast from the city. The darkness of the cityscape disappears with the dawn, and the urban highway literally dissolves into the rural lane and trees in the country. A musical cue begins as the drive and continues until their journey, set in montage, has ended. It is a simple melody supported by a sparsely scored rhythm section. The framing of the shot in the car showing Deniz in the driver's seat, Lale in the passenger seat, and the road outside of the windshield suggests the music might be on the radio. But when the road dissolves and the city with it, the track continues without break, establishing it as non-diagetic. Strangely, the instruments are difficult to place. The harmonic and rhythmic support of the rhythm section is provided by a synthesized drum track. The melody, set in a simple style not unlike a folksong, is performed on an instrument of indeterminate origin. It might be a synthesizedney, mey, or clarinet, or at the very least might be a heavily processed live performance. In either case, the sound of the music yields few timbral details as to how the audience is to classify and understand it. Here the monophonic setting - melody and simple percussive accompaniment - evokes the suggestion of non-Western music. The sound of the instrument is altered by a lo-fi radio effect to the point that its crackly: its timbre recalls a lost past by sounding as if it comes from a scratchy record. Together these sonic elements parallel the narrative and visual 'return to home.'

A second example from Dün Gecebir Rüya Gördüm demonstrates how the 'return to home' trope changes and yet remains the same when scored with a selection of aranjman, a genre of Western music adapted by Turkish musicians. In this scene, Lale has returns to the relative safety of her father's apartment somewhere in the city and has a few calm moments to herself. She sits in her childhood bedroom sorting through objects from her past. She finds items that belonged to her mother, and we see she is still grieving over the loss of a person who has died long ago. As she is sorting through these items, pining for her lost mother, a simple melody plays to emphasize her grief. The setting of this melody features a synthesized cello and what is most likely a ney, the endblown cane flute most commonly associated with the Mevlevi dervishes and Ottoman musical forms. However, the melody is not Turkish at all. Rather it is the American folk song "You Are My Sunshine," first recorded in the Southern United States in 1939. ${ }^{15}$ 
The sweet and somewhat plaintive quality of the arrangement speaks to how the loss affects Lale, and perhaps explains many of her troubles. The poignancy of the song and its setting are entirely appropriate for the emotional moment, and would fulfill the symbolic and aesthetic expectations of international film audiences. That the director Ulaş Ak and composers and music directors Bora Ebeoğlu and Cengiz Onural would choose to use this particular song at this moment suggests they intend to bring the text's meaning to the scene-which would assume some degree of recognition on the part of the audience. The nostalgia of the moment, part of the trope of returning to home, is deepened by the implications of the song's lines, "you are my sunshine/ my only sunshine/ you make me happy/ when skies are grey." It is a moment that follows the form of the earlier homecomings but employs a different strategy to enlist a folk melody to evoke the emotion of the homecoming. Although this is an American folk song, it is part of Turkish musical vernacular because it an example of the aranjman genre, and recognizable as such. However, the filmmaker's use of it to complete a 'return to home' sequence, demonstrates flexibility in the formal construction of this trope. The music adds to the poignancy of the parent-child relationship, which Suner identifies as a definitional feature of many nostalgia films, and indeed new Turkish cinema in general. ${ }^{16}$ Here we see the aesthetics of Yeşilçam and post-Yeşilcam era (roughly 1952-1990) melodramas are still largely guiding the formal constructions of Turkish cinema as a whole. ${ }^{17}$

Importantly, the combinatorial project that joined the new formalized Turkish folk culture, urbanized pop culture, and poached Western cultural influences created an aesthetic of combination, or apparent synthesis. Savaş Arslan calls the process of borrowing "Turkification," rather than simply "Westernization." 18 The difference lies in that "Turkification" is not a top-down regime of change, but a chaotic process of adapting and poaching elements of Western films for a wide range of competing reasons. The aranjmangenre, like arabesk is itself a product of this time and tendency, the former adapting Western influences while the latter introduced Arab cultural products intoTurkish cinematic and musical life. ${ }^{19}$ The music we hear when Lale is home with her mother's belongings is part of a process of this adaptation, and the synthetic nature of the music is less about 'Westernizing' the film score, than it is about using music that is meaningful to audiences. Its 'Western' qualities have attained such a degree of unquestioned banality that they can be overcome by the relatively superficial 'Turkish' timbres and performative details, i. e. the sounds of Turkish instruments and monophonic settings alone.

This process is never complete however. As Arslan states, "Turkification may be thought of as a process of coexistence between the West and the East, with various failures, novelties, and aggressions." ${ }^{20}$ The two idioms must exist together in a perpetual dialectical opposition for the aesthetic to be fulfilled. Like parody, where the original and the comical version must be apparent simultaneously for the joke to work, 'West' and 'East can never be truly synthesized. Their traces in the music be present and available to the ear at all times - whether they are attended to consciously or not. The musical moments accompanying the 'return to home' tropes have all borne the truth of this fact. The incongruences of their presentation present different strategies of maintaining this uneasy pairing. In fact, the music is often the locus of this process. It brings the alternative readings or the contemporary struggles to moments constructed to solve the tension between the relationship.

The 'return to home' trope can be found in all types of film, including action dramas. However, its presencedoes signal the influence of a melodramatic aesthetic or the use of narrative devices borrowed from melodramas. One example is the recent film New York'ta Beşs Minare (Five Minarets in New York, 2010) by actor, writer, director Mahsun Kırmızı̈ül (score by Yildiray Gürgen and Kırmızıgül). Ostensibly an action film dealing with issues surrounding the international pursuit of fundamentalist terrorists, this film is a troubled attempt to treat these issues, expound Kırmızıgül's philosophies about Islam and the United States, and focus on a Turkish-centric storyline. The story follows Turkish police officers Firat (Mahsun Kırmızı̈̈l) and Acar (Mustafa Sandal) as they chase a powerful terrorist leader called 'Dajjal' to New York. There they arrest an import shop owner and mystic Haci Gumuş (Haluk Bilginer) believing he is the terrorist they were sent to find. After many 
difficulties, they succeed in repatriating Haci to face Turkish justice, only to realize he is innocent. This story arc takes up three quarters of the film and adheres closely to the usual formal characteristics of an action film: quick cutting, a number of visual effects, gratuitous violence, and few moments of dialogue. The last quarter, however, begins with the revelation that Firat was decieving the authorities to get close to Haci. We learnFirat, believing Haci murdered his father, fabricated stories about Haci to bring him back to Bitlis, their hometown, to exact revenge.

The title Five Minarets in New York actually refers to the five minarets at the Gökmeydan mosque in Bitlis, a well-known village in eastern Turkey. Within the context of the film this title suggests that events in the past, even in Bitlis, can have a profound effect even as far away as New York. This essentially explains how the film, while mostly aprocedural police action-drama about international terrorism, is actually a melodrama dealing with the aftermath of a family feud that led to a cold-blooded murder. The importance of the events in Bitlis - the intrusion of the past and Anatolian time-space - affects even the events in New York. Everything within this film pushes to the final moment where Haci is murdered by Firat's grandfather in retribution for his part in the revenge killing actuallyperpetrated by his older brother. The entire arc of the film is in aid of an emotional return to the home he escaped and the permanence of one's connection to the past.

Haci's 'return to home begins' once the charges against him have been dropped. He decides to go home to visit his estranged mother and face the memories of Bitlis. The turning point of the film comes when Firat, Acar, Haci and Haci's wife leave Atatürk airport after seeing off Marcus, his faithful American friend and advisor. The oversaturated shot of the white and steel interior of Atatürk airport's lobby is interrupted by a long-shot of their SUV on a road in the country. Firat and Acar are taking them through the Anatolian interior, and the camera cathes them as they drive along a road with the coast of a lake, presumably lake Van, on one side and the scrubby rural-landscape on the other. To emphasize the pastoral nature of the scene a herd of goats obstructs their passage and forces them to get out of the car. Standing at the water's edge, they examine the horizon anddiscuss the emotions and meaning of the moment.

The music for the sequence follows the format of the trope exactly. It is a synchretic setting (in Chion's sense) with clear intent to be so; the musical score is there to mirror the shift form the city to the countryside. A piano and string orchestra figure begins during Marcus' departure from Istanbul and lingers over the jump cut. It is consequently drawn into the travel sequence, suturing the two spaces and softening the disjucture. At the very moment of the cut, the cue thickens with the addition of a def and darabuka accompaniment. This continues as their SUV rounds the bend and encounters the goats, at which point a mey and instrument strongly associated with Eastern Turkey and Kurdish southeastern Turkey plays a non-committal phrase. By this, I mean that this musical moment is a collection of indistinct motives too insubstantial to constitute a melody or phrase. Instead, like the framing of the road itself, they are evocative without denoting anything. Visually this moment could be referring to any part of Turkey where there is water and a rural landscape - even the Aegean coast. Musically, the cue is relying on the connotations of the sounds of the instruments to refer to a rural space and a return to the past.

Gürgen's insubstantial scoring persists as they arrive in Bitlis. It is only when Haci walks up the steps to his mother's home, a ruin of astone house that the cues solidify. With every step, a new layer of music consisting of short indistinct snatches of folk songs (each seemingly coming directly from an archive of ethnographic recordings) overcomes the earlier music. Each new addition obscures more and more of themusics' clarity, and the heavily accented voices compete with each other for dominance. The songs are reduced to snatches of surface elements, timbre, the singer's accent, and short motives, because coherent melodies and rhythmic structure are destroyed in the mix. This cacophony of Anatolia's musical past subsides as a single female voice wins out 
singing "Geceler yarim oldu/ Anne ağlamak karım oldu," the first line of the well-known şarkı. The setting is in the style of a contemporary türkü performance: a single voice singing in an unmetered uzun hava with an improvised saz accompaniment. The singer is crying out to anne (mother), which instantly betrays the intent behind the cue. But despite being a rather heavy handed treatment, this cue captures the very essence of the 'return to home.' The rural family home, the loss suffered by leaving for the urban and modern world, and the painful baggage of the past are all combined in a single moment.

These musical connections are not coincidental. Gürgen and Kırmızıgül, who had a career as a pop singer, score these moments to match the passage from the modern world, through the intermediary space of the road, and into the rural past. As Haci moves along this path, the score slowly sheds its dualistic features where it openly bears the makrs of the urban/rural or present/past pairing. The piano and strings give way to connotations of the rural/past conflation, and finally yield to an old song which is afforded a great deal of emotional import and ends the sequence. Musically, the sequence is unique in the film. Haci's first step across the threshold of his mother's home is musically the most intense, and the most deliberatly scored moment in the film. His return to his roots is significant, and marked as suck. However, it is not this music that returns when he finally reveals his identity to his mother, who is now blind and unable to recognize her son. Rather the pattern of devolution established during their travels reverses. The cue as he reveals his identity is an indistinct set of short phrases played on the saz with string orchestraaccompaniment. Immediately after this, Haci is shot and dies. Although interrupted by the gunshot, the final minutes of the score are return to the blended idiom of the initial 'return to home' cue - strings supporting a few short motives performed on a low ney (possibly synthesized). Haci's final moments are scored with a full orchestra, choir, and eventually harp, in a functional setting that continues until the end titles. Ultimately, his story is set to a conventional film score which excises any deliberately 'Turkish' features. This final statement obscures the logic of the 'return to home,' but demonstrates how the musical settings for these moments speak to a larger discourse about the markers of identity. Music can build an emphatic statment of Turkish identity built upon the past and the rural roots of the audience, but it can also undercut this assertion and assert a dualistic, or multiplicitous reading of the same indentity construction. The music in these settings, like the other statements of the 'return to home' both construct an ideal past and subtly undo it. Ultimately, the nostalgia is always set in the idiom of the present and refereneces a fictional past. The musical settings for these moments speak to this truth very strongly.

\section{Conclusion}

In the same way that a photograph showing only part of a scene or an object for sale suggests a more romantic whole, the incompleteness of these musical moments leave much to the imagination. The musical contribution to the 'return to home' trope is insubstantial yet powerfully evocative, in that it requires the individuals in the audience to fill in what is missing. It connotes a past and its traditions while denoting almost nothing - neither East nor West. Consequently, the stylistic features of the music take on the most import, while the melodic construction, harmonic practices, and orchestration remain hidden, lest they betray the fiction of the moment. Motives, or short incomplete phrases, stand for melodies. Harmonic forms are interrupted and left incomplete. Songs only manage to finish a single line of text. Often, because only the sounds of the instruments are available to the audience, they become meaningfulsimply because of their presence. A cue can be an index for 'Turkish' simply by presenting a Turkish instrument. The unconsummated nature of the sign (in Langer's sense) facilitates the co-presenceof an unresolved dialectical pairing bringing East and West, modern and past, urban and rural together simultaneously. ${ }^{21}$ Opposed by their continued juxtaposition, the stylistic elements denoting 'Turkishness' or 'Western' are not synthesized in the musical presentation, but rather occupy the same space 
unable to overcome one another. This reflects the result of the struggles identified by Zaim and spoken through his character Eflatun. The meaning of the 'return to home' - based in a constructed nostalgia or shared memory of loss - does not end with a clean synthesis, but allows this unresolved dialectical pair to stand. The past and the present, the urban and rural are experienced together. The process of identification exemplified in these cinematic moments arises from the dual (at least) nature of self which transcends this stalemate. The paradoxes, contradictions, and strategies that produce the different iterations of the 'return to home' demonstrate the complex nature of this process of identification and the impossibility of any singular resolution.

Here Boym's distinction between restorative and reflective nostalgia where the first "puts emphasis on nostos and proposes to rebuild the lost home and patch up memory gaps" and the latter "dwells in algia, longing and loss, the imperfect process of rememberance" becomes blurred and problematic. ${ }^{22}$ The efficacy of the "return to home' turns on its appeal to a general sense of loss while actively presenting the restoration of home. Thus, loss and restoration appear together at the same time. However, neither the loss nor the home that is regained are part of a history shared by all Turks. This means neither isa sufficient condition for identity formation. The music sutures the disparate segments together and universalizes the moment. With its aid 'return to home' is able join the emotional power of both loss and restoration to create a single common myth capable of speaking to all audiences. The music is the marker and generator of this connection and through it the discursive process of identity formation is given a voice. It is the score that fulfills Eflatun's promise.

${ }^{1}$ G. Dönmez-Colin (2008), Turkish Cinema: Identity, Distance, and Belonging, London: Reaction Books, p. 189.

2 Ibid.

${ }^{3}$ O. Tekelioğlu (1996), The Rise of a Spontaneous Synthesis: The Historical Background of Turkish Popular Music, Middle Eastern Studies 32(2): pp. 194-215.

4 This may seem to be a rather wordy way to say this, but I want to focus on 'processes of identification' rather than talk about 'identity' because of our tendency, when using the latter, to objectify and reify something which has no solidity or objective reality. The notion that 'identity' as an object is simply an impossibility. Instead we should see it as a resultant symptom of a social discourse interacting with a nearly infinite set of individualistic (and entirely idiosyncratic) processes of self-(re)formation.

${ }^{5}$ Cf. K.I Signell (1976), The Modernization Process in Two Oriental Music Cultures: Turkish and Japanese, Asian Music 7 no. 2, pp. 72-102; M. Stokes (1992), Islam, the Turkish State and Arabesk, Popular Music 11, pp. 213-227; M. Stokes (1992), The Arabesk Debate, Oxford: Oxford University Press; M. Stokes (1992), The Media and Reform. The Saz and Electrosaz in Urban Turkish Folk Music, British Journal of Ethnomusicology 1, pp. 89-102; J. M. O'Connell (2000), Fine Art, Fine Music: Controlling Turkish Taste at the Fine Arts Academy in 1926, Yearbook for Traditional Music 32, pp. 117-142; Tekelioğlu (1996).

${ }^{6}$ This seems to be the case with at least some audience members. In the course of several interviews I have conducted between 2007 and 2010, many casual viewers (those who are not specialists in film or music) were unaware that polyphonic practice or orchestral ensembles were anything other than normative, and therefore, Turkish music. 
7 S. Boym (2001), The Future of Nostalgia, New York: Basic Books, p. xiii.

${ }^{8}$ Boym (2001), p. xv.

${ }^{9}$ Boym (2001), p. xv-xvi.

10 Z. Gökalp (1959), Turkish Nationalism and Western Civilization, trans. Niyazi Berkes, Westport, CT: Greenwood Press.

${ }^{11}$ M. Billig (1995), Banal Nationalism, London: Sage Publications.

12 E. Özyürek (2006), Nostalgia for the Modern, Durham, NC: Duke University Press.

${ }^{13}$ A. Suner (2010), Turkish Cinema: Belonging, Identity, and Memory, London and New York: I. B. Tauris.

${ }^{14}$ My purpose in using this example is to give a relatively simple caseof the trope that is common in a sufficient number of Turkish films and television programs to constitute a true trope with a host of significant meanings and interpretations. It is never possible to find a 'pure' example - which is part of my larger point-and so this one was chosen because it is a relatively orthodox presentation of this cine-musical sign complex and is recognized as such by the Turks I have worked with. However, because part of my argument involves themes found in films coded as 'Turkish' it is certainly worth discussing the origin and nationality of the composer EvanthiaReboutsika. She is not a Turk. She is Greek and was educated as a musician and composer at home and in Paris. In this she has a background similar to many Turkish composers who write for films, television, and commercials. Many of those working in the Turkish film industry were also educated in Western classical techniques and attended foreign institutions, particularly in Germany and the U. S. Furthermore, the origin of the composer is not entirely applicable here because of the collaborative nature of filmmaking. Her contributions had to be performed by musicians, adapted by the musical supervisor, edited by the editor, and mastered by the sound engineers, all of whom have a great deal of impact on the final musical product. Ultimately, it is also usually the director that has final say over the location, use, applicability, and meaning of any particular musical moment. Because of these reasons, the fact she is not a Turk is largely beside the point.

15 The Pine Ridge Boys (1939), You Are My Sunshine. Bluebird Records. Recorded August 22, 1939.

${ }^{16}$ Suner (2010), p. 35.

17 Suner (2010).

${ }^{18}$ S. Arslan (2010), Cinema in Turkey: A New Critical History, Oxford: Oxford University Press.

19 Stokes (1992); M. Stokes (1989), Anthropological Perspectives on Music in Turkey (Ph. D. Diss. Oxford University); M. Ergin (2000), Arabesk: Music, Culture and Politics in Turkey (master's thesis, University of Minnesota).

${ }^{20}$ Arslan (2010), p. 18.

21 S. Langer (1957), Philosophy in a New Key: A Study in the Symbolism of Reason, Rite, and Art, $3^{\text {rd }}$ ed, Cambridge, MA: Harvard University Press.

${ }^{22}$ Boym (2001), p. 41. 
Paul Hartley is a Ph.D. candidate in Musicology-Ethnomusicology at the University of Illinois at UrbanaChampaign. He is currently in Turkey as a IIE-Fulbright scholar conducting research for his dissertation on the production, reception, and socio-cultural implications of film music in contemporary Turkish cinema. He is especially interested in examining mass-mediated music's role as a vector of socio-cultural detail and its place as an important point of social interaction between large populations. Consequently, he works across many disciplines, including musicology, philosophy, sociology, anthropology, cinema studies, communications, music informatics, digital humanities, and cultural studies. In addition to being a musicologist, he is also a clarinetist. 